\section{All fishing nations must unite to cut subsidies}

SIR - The threat of overfishing to world fisheries is well documented, but not enough attention has been paid to government subsidies as an important factor in their decline. Subsidies, or government payments to the fishing sector, estimated at US\$30-34 billion a year, are key drivers of the unsustainable exploitation of the world's depleted fish populations. Fish are the main source of protein for one fifth of the world's population, but global fishing fleets are more than double the size the oceans can support.

If fisheries are to become sustainable, overfishing subsidies must be significantly reduced (U. R. Sumaila et al. Fish. Res. 88, 1-4; 2007). Unfortunately, unilateral action by individual countries may not work, because their fisheries could then be at a disadvantage in the competitive global market for fish; also, fish do not respect national boundaries and fishing fleets operate worldwide. The only effective approach to the subsidy problem is through multilateral action, in which all fishing nations end or reduce these subsidies under similar rules.

The World Trade Organization (WTO) has 151 member countries and a mandate to level the trade playing-field for every country. It is in a unique position to tackle the global problem of overfishing subsidies and to move fisheries towards sustainability, because it is the only global institution, apart from the Convention on International Trade in Endangered Species of Wild Fauna and Flora, that has mechanisms in place to enforce its agreements.

The WTO is at present drawing up terms, including terms on how to police fisheries subsidies, in the Doha round of negotiations. We urge the WTO to seize this opportunity now, to forestall the predicted collapse of the world's wild fish populations.

U. Rashid Sumaila ${ }^{\star}$, Daniel Pauly'

${ }^{\star}$ Fisheries Economics Research Unit, Fisheries Centre, The University of British Columbia, $\uparrow$ Fisheries Centre, The University of British Columbia, AERL Building, 2202 Main Mall, Vancouver, British Columbia V6T 1Z4, Canada

\section{Debate over flood-proofing effects of planting forests}

SIR - William Laurance, in his News \& Views article 'Forests and floods' (Nature 449, 409-410; 2007), highlights a paper by C. Bradshaw and colleagues, claiming that it provides correlative evidence that native forests reduce the frequency and severity of floods in developing countries.

The 'forest and floods' debate goes back at least to the nineteenth century. Now forest hydrologists generally agree that, although forests mitigate floods at the local scale and for small to medium-sized flood events, there is no evidence of significant benefit at larger scales and for larger events.

Laurance also recognizes the omission of extreme events in the Bradshaw analysis. But we argue that this seriously weakens the policy importance of the results. It is these extreme events that matter: economic damage and loss of life grow exponentially with flood magnitude. The authors also excluded Chinese data because of outliers an unfortunate omission, given that China has undergone large changes in forest cover where the flood 'signal' should be strong.

Laurance did not discuss Bradshaw and colleagues' other conclusion, namely that increasing the number of forest plantations can lead to longer and more frequent floods. For China, where initiatives such as the sloping-lands conversion programme heavily promoted on the basis of floodmitigation benefits - are leading to forest plantation over areas comparable to those of afforestation by the rest of the world put together, the conclusion is particularly important. Other studies have warned that forest-management activities can aggravate flood risk (see J. A. Jones and G. E. Grant Water Resources Res. 32, 959-974; 1996). Ian R. Calder ${ }^{\star}$, James Smyle $†$, Bruce Aylward ${ }^{\star}$ Centre for Land Use and Water Resources Research, Newcastle University,

Newcastle NE1 7RU, UK

$\uparrow 149$ East Rosewood Avenue, San Antonio, Texas, USA

Ecosystem Economics LLC, PO Box 2062, Bend, Oregon 97709, USA

\section{Motivation needed to cure lifestyle diseases}

SIR — David A. King and Sandy M. Thomas in their essay 'Big lessons for a healthy future' (Nature 449, 791; 2007) describe how, in Western societies, "growing recognition of how science can contribute to health, well-being and the economy" is leading to governmental attempts to control public health. Their Foresight study suggests that by 2050 , in the United Kingdom, about $60 \%$ of men, $50 \%$ of women and $25 \%$ of children will be obese, and that the associated chronic health problems will cost an additional $£ 45.5$ billion (US $\$ 93$ billion) a year. To combat this, the authors propose a strategy similar to that used for climate-change policy, in which six chief advisers (and their entourages) of government departments developed a 'top-down' strategy.

Such a paternalistic approach is reminiscent of past attempts to eradicate cholera and smallpox by better sanitation, housing and vaccination. However, today's lifestyle-related diseases, such as obesity, type-2 diabetes mellitus and cardiovascular disease, are different. They develop slowly, in response to chronic food intoxication and lack of exercise, causing a long-lasting imbalance between excess energy intake and insufficient energy expenditure. And they require a different approach.

Paternalistic health-care systems will be of little avail because they fail to activate the individual's motivation to care continuously for his or her own health, which is necessary for success. To secure such motivation, there would have to be annual financial incentives for those complying, with set targets as to body weight and physical strength. Such incentives could be tax breaks, or a partial annual cash refund of private healthinsurance premiums. The aim would be absence of lifestyle-related disease at the age of 60. An addressable target group for such incentives could be people aged 35-55 who care for children and/or elderly family members, as additional pressure from their dependants might help to secure compliance with health targets.

Werner Waldhäusl

Department of Internal Medicine III, Medical University of Vienna, Währinger-Gürtel 18-20, 1090 Vienna, Austria

\section{Educational success must start in Pakistan's schools}

SIR - Your Editorial 'The paradox of Pakistan' (Nature 450, 585; 2007) rightly credited General Pervez Musharraf's regime for increased spending on science and research, which may be threatened by the political decline of Musharraf. I would like to add that the fall of such an ambitious scientific enterprise is built into the educational system of the country at primary and secondary levels. Universities simply cannot produce quality research and education if fiscal resources are not accompanied by quality human resources.

The students at Pakistan's universities come from a vastly neglected school and college system. Unless the lower-tier educational institutes are able to produce quality pupils, the money spent on universities is going to be wasted. The school education system must be thoroughly overhauled so that universities can make the best use of available resources.

Masroor Bangesh

Institut für Anorganische und Analytische Chemie, Friedrich-Schiller Universität Jena, Carl-Zeiss Promenade 10, 07743 Jena, Germany

Contributions to Correspondence may be submitted to correspondence@nature.com. We also welcome comments and debate at http://blogs.nature.com/nautilus. 